\title{
Tuberculum sellae meningiomas: grading scale to assess surgical outcomes using the transcranial versus transsphenoidal approach
}

\author{
Stephen T. Magill, MD, PhD, ${ }^{1}$ Ramin A. Morshed, MD, ${ }^{1}$ Calixto-Hope G. Lucas, BS, ${ }^{1}$ \\ Manish K. Aghi, MD, PhD,1 Philip V. Theodosopoulos, MD, ${ }^{1}$ Mitchel S. Berger, MD, ${ }^{1}$ \\ Oreste de Divitiis, MD, ${ }^{2}$ Domenico Solari, MD, PhD, ${ }^{2}$ Paolo Cappabianca, MD, ${ }^{2}$ \\ Luigi M. Cavallo, MD, PhD, ${ }^{2}$ and Michael W. McDermott, MD1
}

\begin{abstract}
'Department of Neurological Surgery, University of California, San Francisco, California; and 2Divsion of Neurosurgery, Università degli Studi di Napoli Federico II, Naples, Italy
\end{abstract}

\begin{abstract}
OBJECTIVE Tuberculum sellae meningiomas (TSMs) are surgically challenging tumors that can severely impair vision. Debate exists regarding whether the transcranial (TC) or endoscopic transsphenoidal (TS) approach is best for resecting these tumors, and there are few large series comparing these approaches.

METHODS A retrospective chart review was performed at 2 academic centers comparing TC and TS approaches with respect to vision, extent of resection, recurrence, and complications. The authors report surgical outcomes and propose a simple preoperative tumor grading scale that scores tumor size (1-2), optic canal invasion (0-2), and arterial encasement (0-2). The authors performed univariate, multivariate, and recursive partitioning analysis (RPA) to evaluate outcomes.
\end{abstract}

RESULTS The TSMs were resected in 139 patients. The median follow-up was 29 months. Ninety-five (68\%) cases were resected via a TC and $44(32 \%)$ via a TS approach. Tumors treated via a TC approach had a higher tumor $(p=$ $0.0007)$, artery $(p<0.0001)$, and total score $(p=0.0012)$ on the grading scale. Preoperative visual deficits were present in $87 \%$ of patients. Vision improved in $47 \%$, stayed the same in $35 \%$, declined in $10 \%$, and was not recorded in $8 \%$. The extent of resection was $65 \%$ gross-total resection, $23 \%$ near-total resection ( $95 \%-99 \%$ resection), and $12 \%$ subtotal resection (<95\%). A lower tumor score was significantly associated with better or stable vision postoperatively $(p=$ 0.0052). The RPA confirmed low tumor score as the key predictor of postoperative visual improvement or stability. Multivariate analysis and RPA demonstrate that lower canal score $(p<0.0001)$ and TC approach $(p=0.0019)$ are associated with gross-total resection. Complications occurred in 20 (14\%) patients, including CSF leak (5\%) and infection (4\%). There was no difference in overall complication rates between TC and TS approaches; however, the TS approach had more CSF leaks (OR 5.96, 95\% Cl 1.10-32.04). The observed recurrence rate was 10\%, and there was no difference between the TC and TS approaches.

CONCLUSIONS Tuberculum sellae meningiomas can be resected using either a TC or TS approach, with low morbidity and good visual outcomes in appropriately selected patients. The simple proposed grading scale provides a standard preoperative method to evaluate TSMs and can serve as a starting point for selection of the surgical approach. Higher scores were associated with worsened visual outcomes and subtotal resection, regardless of approach. The authors plan a multicenter review of this grading scale to further evaluate its utility.

https://thejns.org/doi/abs/10.3171/2018.1.FOCUS17753

KEYWORDS tuberculum; meningioma; grading scale; endoscopic; transsphenoidal; expanded endonasal approach; complications; outcomes; sella; sellae

\footnotetext{
ABBREVIATIONS ACA = anterior cerebral artery; EOR = extent of resection; GTR = gross-total resection; ICA = internal carotid artery; NTR = near-total resection; RPA = recursive partitioning analysis; STR = subtotal resection; TC = transcranial; TS = transsphenoidal; TSM = tuberculum sellae meningioma; UCSF = University of California, San Francisco.
}

SUBMITTED December 2, 2017. ACCEPTED January 16, 2018.

INCLUDE WHEN CITING DOI: 10.3171/2018.1.FOCUS17753. 
$\mathrm{T}$ ubERCULum sellae meningiomas (TSMs) are challenging tumors because of their proximity to the optic nerves, the internal carotid artery (ICA), and the anterior cerebral artery (ACA), as well as the hypothalamus, infundibulum, and pituitary gland. Even small tumors can cause significant morbidity by compressing the optic nerve. Almost all TSMs invade the optic canal to some extent. ${ }^{25}$ In the literature, TSMs are often grouped with suprasellar or parasellar meningiomas and included in analysis with planum meningiomas. ${ }^{22}$ However, true TSMs are distinct from planum meningiomas in that they are centered on the tuberculum, they grow posteriorly and superiorly, and they displace the optic nerves superiorly and laterally. Visual impairment is the primary indication for surgical treatment, whereas radiotherapy can be considered for asymptomatic TSMs without mass effect on the optic nerve.

Transcranial (TC) microsurgical resection has been the standard of care and has a proven track record of good outcomes, with the majority of patients having improvement in visual function postoperatively. ${ }^{8,9,13,19,21,23,24,30}$ The TC approaches commonly used include the extended bifrontal, tailored bifrontal, ${ }^{26}$ interhemispheric, orbitozygomatic, pterional, and subfrontal eyebrow ${ }^{30}$ approaches. However, with advances in endoscopy ${ }^{7}$ and the subsequent development of the expanded endonasal approach, ${ }^{14}$ there has been significant debate among practitioners in the neurosurgical community as to whether TSMs should be approached transcranially ("from above") or endonasally and/or transsphenoidally ("from below"). ${ }^{2,5}$ The advent of the nasoseptal flap ${ }^{11}$ and increased experience have markedly reduced the $\mathrm{CSF}$ leakage rate that initially complicated expanded endonasal skull base approaches. ${ }^{5}$ These technical improvements have established the transsphenoidal (TS) approach as an important option for appropriately selected TSMs. ${ }^{4,12,16}$

The question of which TSMs should be resected transcranially and which should be approached transsphenoidally remains paramount. ${ }^{17}$ Several series have compared approaches and attempted to define which patients are best suited for each approach;,1,20,22 in one of these series a preoperative grading scale was proposed, but the scale was not significantly associated with outcome. ${ }^{22}$ Thus, there remains a need for a simple preoperative grading scale that is validated in a large contemporary patient series to assist surgeons as they consider the best approach for each patient. Here, we report surgical outcome data from 2 academic medical centers and propose a simple grading scale that can provide a starting point for surgical approach selection.

\section{Methods}

\section{Study Design, Setting, and Participants}

This is a retrospective chart review conducted at 2 large academic medical centers. Both centers are local neurosurgical referral centers, and the primary surgeons are experienced in both open cranial and endoscopic TS surgery, performing more than 50 open and endoscopic tumor resections each year. Patients were included if they were $\geq 18$ years old and had undergone TSM resection at our institu- tions between 1997 and 2016. Magnetic resonance images of each patient's tumor and operative notes were reviewed by the senior authors (L.M.C., M.W.M.). Tumors that were centered on the planum were not included in this study. The patient information, variables, and tumor information were obtained from the medical record and radiology, pathology, and operative reports. Follow-up was based on the clinic notes in the medical record, and the last clinic note or film review note was included as the final followup date. The manuscript was drafted consistent with the STROBE (Strengthening the Reporting of Observational Studies in Epidemiology) statement. ${ }^{29}$ The internal review board at our institution approved this study.

\section{Variables Studied}

Demographic variables included age, sex, and followup duration. Surgical variables included surgical approach, grouped into TC or TS approach. The TC approaches included orbitozygomatic, orbitofrontal, subfrontal eyebrow, extended bifrontal, or midline interhemispheric. The TS approaches included microscopic and endoscopic approaches, with most of the endoscopic procedures using an expanded endonasal approach with nasoseptal flap closure. Clinical variables collected included presenting symptoms, preoperative visual deficits, postoperative visual deficits, extent of resection (EOR), tumor recurrence, and perioperative complications. Complications were grouped into infection, CSF leak, and other.

Outcome variables included visual function, EOR, recurrence complications, and tumor grading scale score. The EOR was classified radiographically as subtotal resection (STR; < 95\%), near-total resection (NTR; 95\%-99\%), and gross-total resection (GTR). The EOR was based on the authors' and radiologists' review of postoperative images, operative reports, and radiology reports. Tumors that had no radiographic residual, but in which the surgeon reported intraoperative residual tumor on the optic nerve or arteries, were considered NTR.

\section{Tumor Grading Scale}

The senior author (M.W.M.) developed the proposed grading scale (Fig. 1) based on his experience resecting TSMs and the anatomical literature. The grading is simple and combines the 3 key tumor characteristics that determined difficulty of resection: tumor size, optic canal invasion, and arterial encasement. The tumor size score receives 1 or 2 points: 1 point if the tumor is $<17 \mathrm{~mm}$ in diameter and 2 points if it is $\geq 17 \mathrm{~mm}$. The diameter of 17 $\mathrm{mm}$ was selected based on 2 anatomical studies that measured the average distance between the optic nerves at the limbus sphenoidale. 6,10 The optic canal invasion score is graded as follows: if the tumor invades $\leq 3 \mathrm{~mm}$ into either optic canal, then it receives 0 points; if it invades $>3 \mathrm{~mm}$ into 1 optic canal, it receives 1 point; and if it invades both optic canals $>3 \mathrm{~mm}$, it receives 2 points. Figure 2 shows a case example with bilateral optic canal invasion. Optic canal invasion can be measured in the coronal plane of a standard stereotactic preoperative MR image. Finally, the arterial encasement score also receives 0,1 , or 2 points. Zero points are given if the tumor does not touch, or sim- 


\section{A Tumor score:}

1: Less than $17 \mathrm{~mm}$

2: Greater/Equal $17 \mathrm{~mm}$

\section{Canal Score}

0 : No Invasion or $(\leq 3 \mathrm{~mm})$

1: Unilateral Invasion $>3 \mathrm{~mm}$

2: Bilateral Invasion $>3 \mathrm{~mm}$

\section{Artery Score}

0 : Abuts medial wall only

1: Envelops $<180^{\circ}$ around artery

2 : Encases $\geq 180^{\circ}$ around artery

D

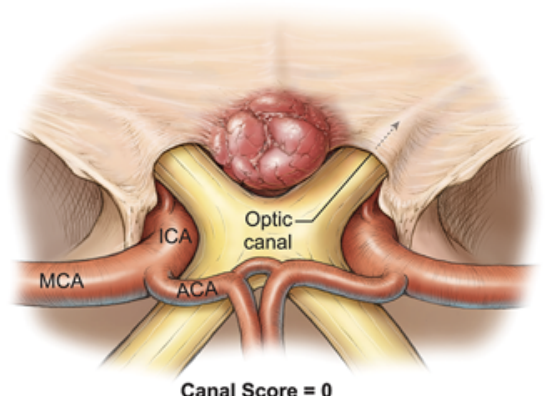

G

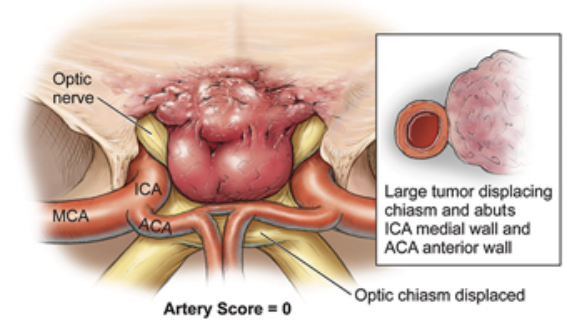

B

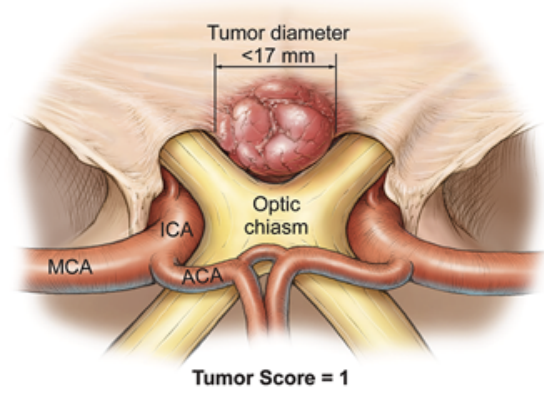

E

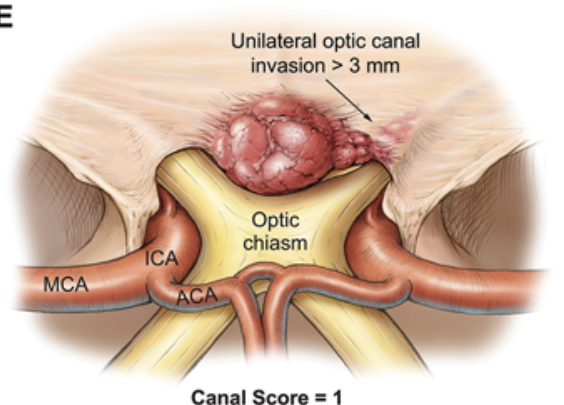

H

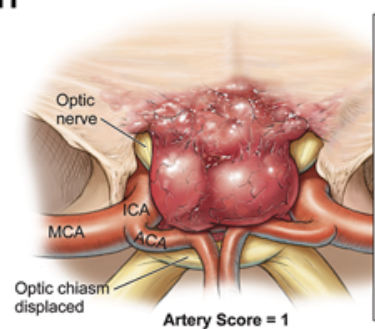

C

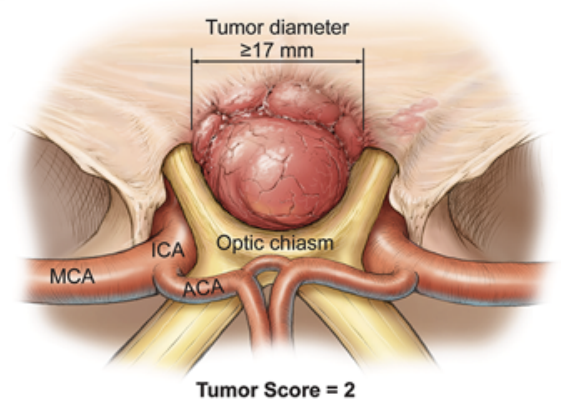

$\mathbf{F}$

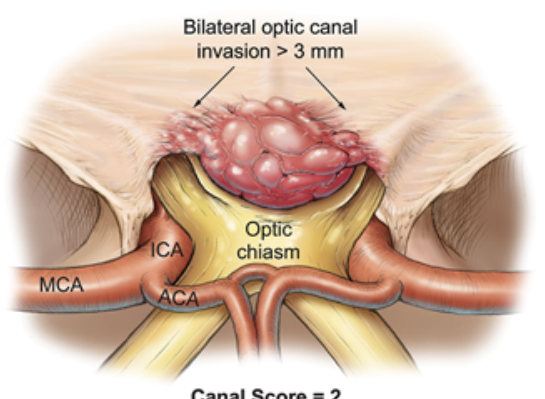

Canal Score $=\mathbf{2}$

I

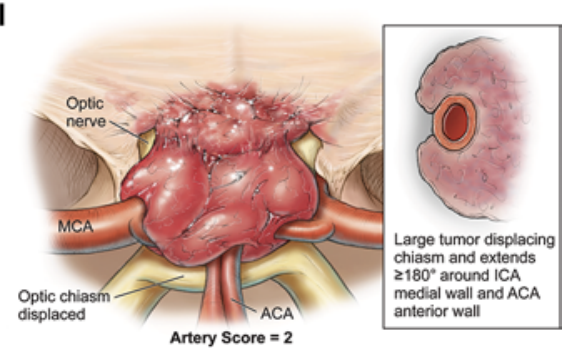

FIG. 1. Proposed TSM grading scale. A: Table showing score ranges. B: Tumors $<17 \mathrm{~mm}$ in diameter receive 1 point. C: Tumors $\geq 17 \mathrm{~mm}$ in diameter receive 2 points. D: Tumors that extend $\leq 3 \mathrm{~mm}$ into either optic canal receive 0 points. E: Tumors that extend into 1 optic canal $>3 \mathrm{~mm}$ receive 1 point. F: Tumors that extend into both optic canals $>3 \mathrm{~mm}$ receive 2 points. G: Tumors that abut the medial wall of the ICA or anterior wall of the ACA receive 0 points. H: Tumors that extend $<180^{\circ}$ around the ICA or ACA receive 1 point. I: Tumors that extend $\geq 180^{\circ}$ around the ICA or ACA receive 2 points. MCA = middle cerebral artery. Panels B-I copyright Kenneth X. Probst. Published with permission.
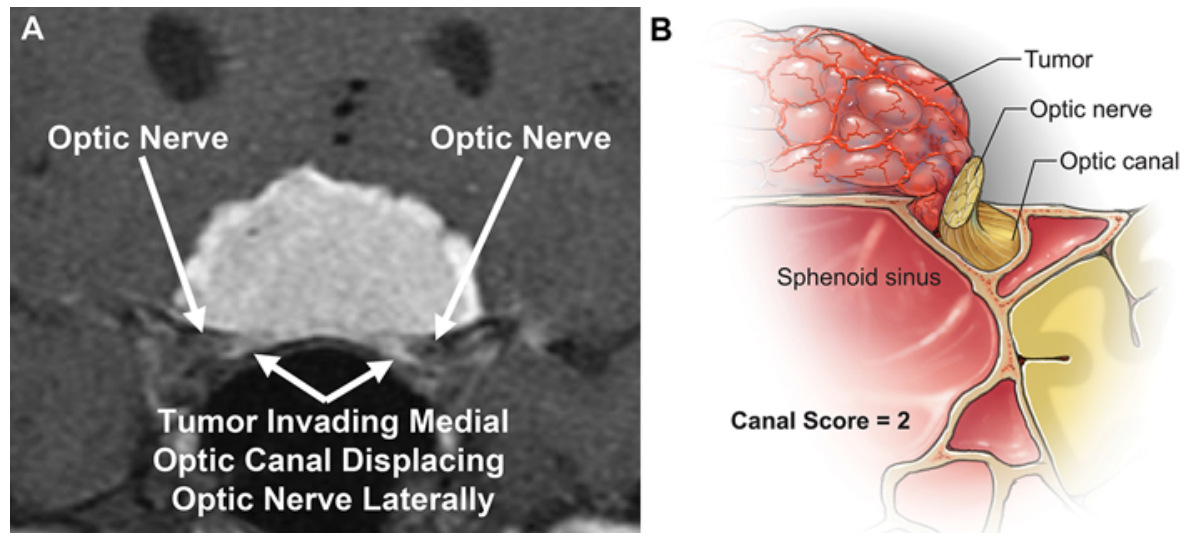

FIG. 2. Optic canal invasion. A: Illustrative coronal postcontrast T1-weighted MR image showing bilateral optic canal invasion by a TSM. B: Artist's rendition highlighting tumor invasion from the medial wall of the optic canal, compressing the nerve and displacing it laterally and superiorly. Panel B copyright Kenneth X. Probst. Published with permission. 
TABLE 1. Demographic and outcome data in 139 patients with TSMs

\begin{tabular}{|c|c|}
\hline Variable & Value (\%) \\
\hline Total patients & 139 \\
\hline UCSF & $104(75)$ \\
\hline Italy & $35(25)$ \\
\hline \multicolumn{2}{|l|}{ Follow-up in mos } \\
\hline Mean, median & $45.7,29$ \\
\hline Range & $0-174$ \\
\hline \multicolumn{2}{|c|}{ TSM grading scale scores (mean, median) } \\
\hline Tumor & $1.7,2$ \\
\hline Canal & $1.2,1$ \\
\hline Artery & $0.9,1$ \\
\hline Total & $3.8,4$ \\
\hline \multicolumn{2}{|l|}{ Approach } \\
\hline Transcranial & $95(68)$ \\
\hline Transsphenoidal & $44(32)$ \\
\hline \multicolumn{2}{|l|}{ EOR } \\
\hline GTR & $91(66)$ \\
\hline NTR; 95-99\% & $30(22)$ \\
\hline STR; $<95 \%$ & $18(13)$ \\
\hline \multicolumn{2}{|l|}{ Postop visual outcome } \\
\hline Better & $65(47)$ \\
\hline Same & $48(35)$ \\
\hline Worse & $14(10)$ \\
\hline Not recorded & $12(8)$ \\
\hline \multicolumn{2}{|l|}{ Recurrence } \\
\hline Yes & $14(10)$ \\
\hline No & $125(90)$ \\
\hline \multicolumn{2}{|l|}{ Complications* } \\
\hline CSF leak & $7(5)$ \\
\hline Infection & $6(4)$ \\
\hline Other & $9(6)$ \\
\hline
\end{tabular}

* A total of 22 complications occurred in 20 (14\%) patients.

ply abuts, the medial wall of the ICA or the anterior wall of the ACA. If it envelops the ICA or ACA $<180^{\circ}$ around the artery, then it receives 1 point. If it encases the ICA or ACA, extending $\geq 180^{\circ}$ around the artery, then it receives 2 points. The senior author at each institution reviewed the MR images to confirm tumor location and assign the tumor grading scale score for each patient.

\section{Study Bias}

This is a retrospective study, and thus it is limited by selection and observer bias. This study is also limited by observer bias in that only information that was recorded in the electronic medical record could be used.

\section{Statistical Analysis}

All statistical analyses were performed in JMP (JMP Pro, Version 13.0; SAS Institute, Inc.). Univariate analysis was performed with Pearson's chi-square test (multiple categories) or Fisher's exact test (2 categories). Multivariate logistic regression was used to test the impact of variables with univariate significance of $p<0.2$ on the outcome of interest. Recursive partitioning analysis (RPA) was performed to identify subsets of patients at risk for the outcome variables. The number of partitions used was based on the maximal $\mathrm{R}^{2}$ value found, with k-fold crossvalidation $(\mathrm{k}=5)$.

\section{Results}

\section{Demographic and Outcome Data}

We identified 139 patients who underwent resection of TSMs between 1997 and 2016. The majority (75\%) of patients came from the University of California, San Francisco (UCSF), and 25\% were from Naples, Italy. A preoperative visual deficit was present in $87 \%$ of patients. Whereas the majority of patients had improved or stable vision $(\mathrm{n}=113,81 \%)$ after surgery, $14(10 \%)$ had worse vision postoperatively. There were $12(9 \%)$ patients without clear postoperative documentation of visual function. The majority of patients had GTR $(65 \%)$ or NTR $(23 \%)$ resections, whereas $12 \%$ had STR. The mean and median grading scale scores are shown in Table 1, with the total mean score 3.8 (median 4). Only 14 patients had tumor recurrence $(10 \%)$, whereas $90 \%$ were recurrence free at last follow-up. At the time of recurrence, 13 patients were treated with radiotherapy, whereas 1 patient underwent repeat resection. A total of 22 complications occurred in 20 patients (14\%), including 7 CSF leaks, 6 infections, and 9 other complications, which included postoperative hematoma $(n=3)$, seizure $(n=2)$, partial hypopituitarism $(n=1)$, diabetes insipidus $(n=1)$, and anosmia and/ or partial ageusia $(n=2)$. There were no perioperative deaths.

\section{Surgical Approaches}

The study population was split between TC $(\mathrm{n}=95$, $68 \%)$ and TS $(\mathrm{n}=44,32 \%)$ approaches (Table 1). The TC/TS ratio was lower in Naples (7:28) compared to UCSF, which was 88:16 ( $\mathrm{p}<0.0001$, Fisher's exact test). For TC approaches, the most common one was the extended bifrontal approach $(\mathrm{n}=50,53 \%)$, followed by the orbitozygomatic approach $(n=25,26 \%)$. Other approaches were performed less frequently $(n=20,21 \%)$ and included pterional $(\mathrm{n}=10)$, midline interhemispheric $(n=7)$, subfrontal eyebrow $(n=2)$, and a tailored bifrontal approach without orbital osteotomy $(\mathrm{n}=1)$. Nearly all the TS approaches were conducted via an endoscopically assisted procedure $(\mathrm{n}=38,86 \%)$, although a small number of operations were performed early in the case series with a TS microscopic approach by a surgeon who had performed more than 1000 TS microscopic cases $(n=6$, $14 \%)$.

We performed univariate analysis to compare complication rates between the TS and TC approaches. There was no significant difference in the rate of any complication ( $p$ $=0.7965)$, infection $(\mathrm{p}=0.6646)$, or other complication ( $\mathrm{p}$ $=0.7191)$. However, CSF leaks were more common with TS $(n=5)$ than TC $(n=2)$ approaches $(\mathrm{OR} 5.96,95 \% \mathrm{CI}$ $1.10-32.04)$. 


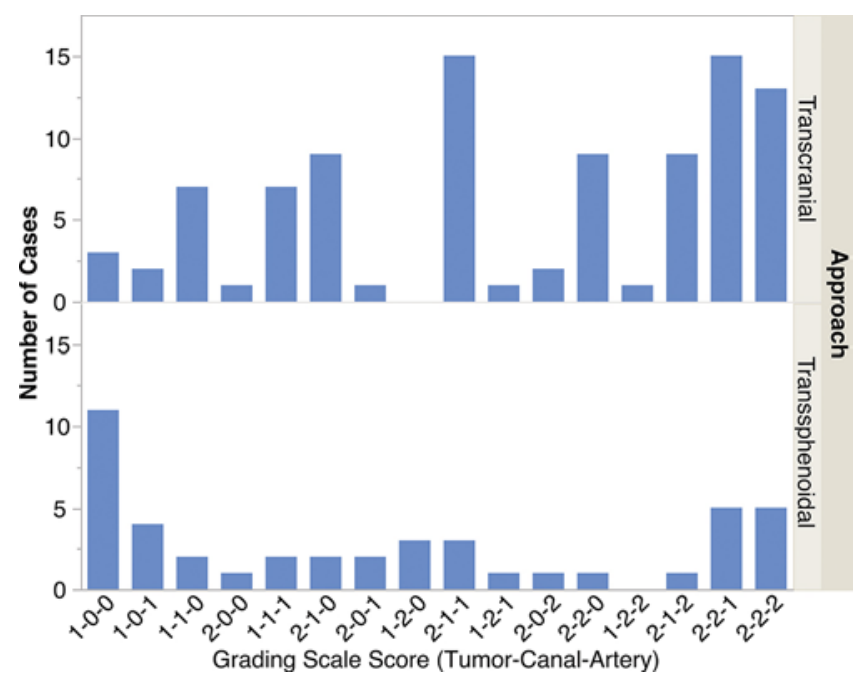

FIG. 3. Frequency of tumors by individual tumor score and stratified by TC or TS approach. The upper histogram shows tumors resected via a TC approach, whereas the lower histogram shows those resected via a TS approach. The tumor grades are shown on the x-axis, with the numbers representing the tumor-canal-artery components of the score. The total score increases linearly from left to right.

\section{Tumor Grading Scale}

Tumors were graded according to the proposed scale (Fig. 1). Univariate analysis was used to compare TC and TS approaches with respect to the proposed grading scale. Tumor score $(\mathrm{p}=0.0007)$, artery score $(\mathrm{p}<0.0001)$, and total score $(p=0.0012)$, but not canal score $(p=0.1770)$, were significantly higher in the TC group. Similarly, tumors resected using the extended bifrontal approach had significantly higher tumor $(\mathrm{p}<0.0001)$, canal $(\mathrm{p}<0.0001)$, and total $(\mathrm{p}=0.0017)$ scores, but not canal score $(\mathrm{p}=0.1246)$, compared to the orbitozygomatic, TS, or other approaches, reflecting the use of the more invasive or wider approach for larger and more aggressive tumors. Taken together, tumors with lower scores were more commonly resected via a TS approach, whereas tumors with higher scores were treated via a TC approach. The higher the score, the more likely that a more invasive approach-e.g., the extended bifrontal approach-was used to resect the tumor. The distribution of tumors categorized by individual tumor score and matched by approach is shown in Fig. 3 .

\section{Risk Factors Associated With Surgical Outcomes}

Postoperative visual function is the most important surgical outcome following resection of TSM. We performed univariate logistic regression on the following variables to determine what factors were associated with better or stable vision postoperatively: preoperative visual deficit, TC or TS approach, EOR (GTR vs NTR or STR), tumor score, canal score, artery score, total score, and any complication (Table 2). The only significant univariate predictor of better or the same visual outcome was tumor score 1 (RR $1.18,95 \%$ CI 1.03-1.30; $p=0.0052$ ). Because all patients with tumor score $1(n=39)$ had stable or improved vision postoperatively, we could not perform multivariate analysis; however, we did perform RPA. The optimal number of
TABLE 2. Univariate outcome analysis

\begin{tabular}{cl}
\hline \multicolumn{1}{c}{ Outcome } & p Value \\
\hline Postop vision better or stable & \\
\hline Preop visual deficit & 0.3469 \\
\hline TC vs TS approach & 0.1374 \\
\hline Tumor score 1 & 0.0052 \\
\hline Canal score & 0.3974 \\
\hline Artery score & 0.1945 \\
\hline Total score & 0.3197 \\
\hline Any complication & 1.000 \\
\hline GTR & 1.000 \\
\hline GTR vs NTR or STR & \\
\hline Preop visual deficit & 0.3732 \\
\hline TC vs TS approach & 0.1799 \\
\hline Tumor score & 0.7043 \\
\hline Canal score 0 & 0.0024 \\
\hline Artery score & 0.1841 \\
\hline Total score & 0.0568 \\
\hline Any complication & 0.3157 \\
\hline Postop visual worsening & 0.9482 \\
\hline
\end{tabular}

Boldface type indicates statistical significance.

splits based on k-fold cross-validation was 1 . We included all univariate variables with $p<0.2$ in the RPA. The split was made on tumor score (Fig. 4A).

For EOR we performed univariate analysis, and only canal score was a significant predictor of GTR ( $p=0.0024$; Table 2). We included all variables with $\mathrm{p}<0.2$ in the multivariate analysis, except for total score, which made the model unstable. Higher canal score decreased the likelihood of achieving GTR, whereas a TC approach increased the likelihood of GTR (Table 3). We performed RPA to identify subgroups based on EOR. The optimal number of splits based on k-fold cross-validation was 3 . The first split was canal score, with canal scores of 1 or 2 having much lower rates of GTR. The second split was on approach, with the TS approach having lower rates of GTR. Finally, the third split was on artery score for patients with a canal score of 0 . In a TSM with an artery score of 1 or 2, we were less likely to achieve GTR (Fig. 4B).

For complications we performed univariate analysis, and none of the following variables were significant predictors of a complication: tumor score $(\mathrm{p}=0.6079)$, canal

TABLE 3. Multivariate analysis

\begin{tabular}{cccc}
\hline GTR & OR & $95 \% \mathrm{Cl}$ & $\mathrm{p} \mathrm{Value}$ \\
\hline Canal score & & & $<0.0001$ \\
\hline 1 vs 0 & 0.05 & $0.01-0.29$ & $\mathbf{0 . 0 0 0 6}$ \\
\hline 2 vs 0 & 0.05 & $0.01-0.28$ & $\mathbf{0 . 0 0 0 8}$ \\
\hline TC vs TS approach & 4.56 & $1.75-11.87$ & $\mathbf{0 . 0 0 1 9}$ \\
\hline Artery score & & & 0.4252 \\
\hline
\end{tabular}

Boldface type indicates statistical significance. 


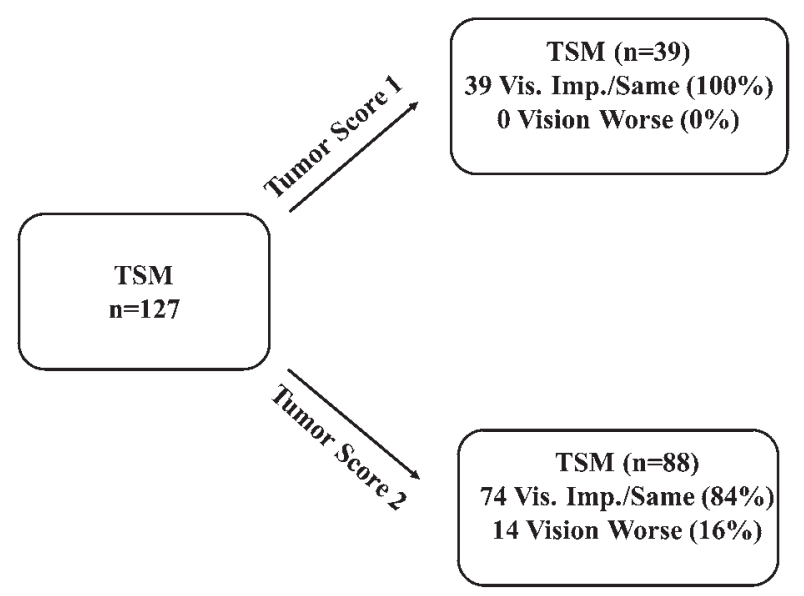

B

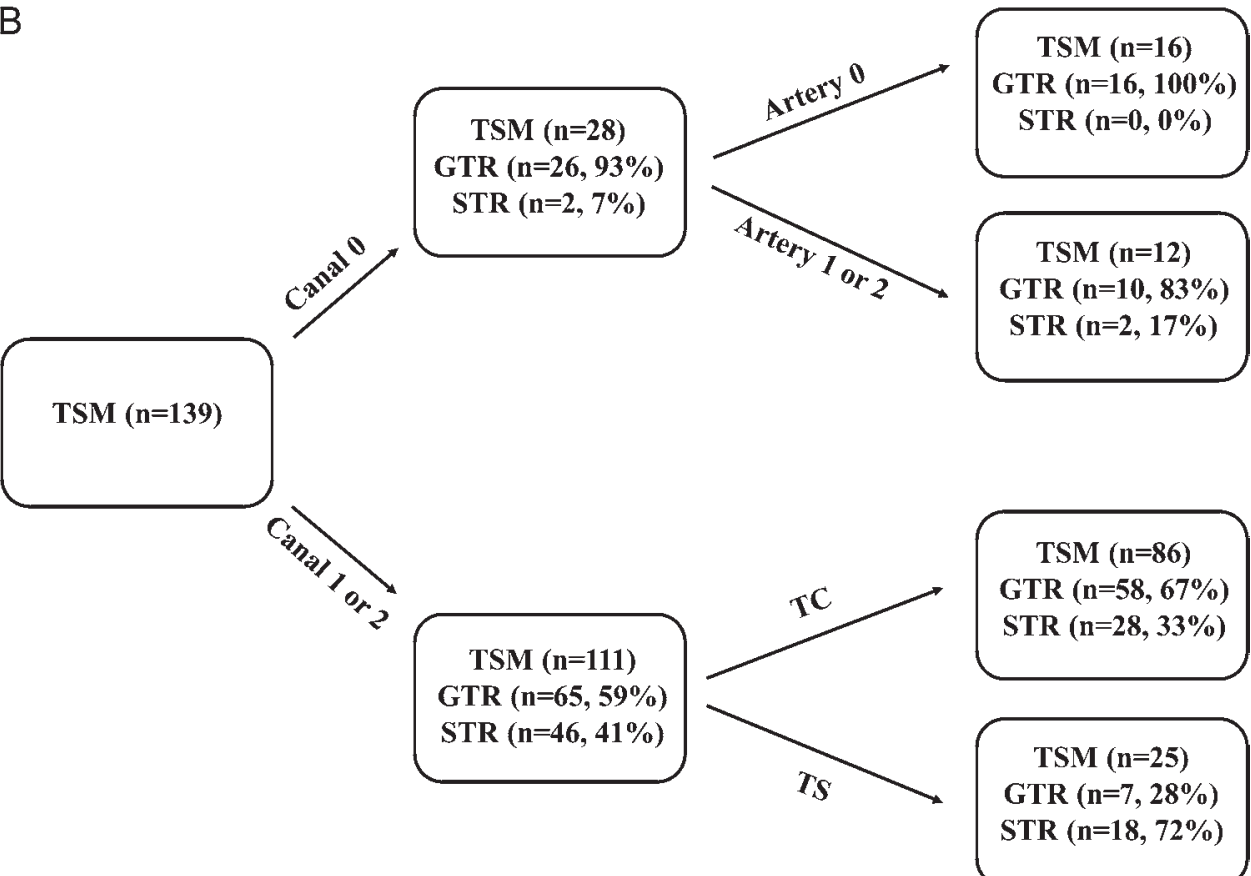

FIG. 4. Schematics showing RPA of risk factors for visual outcome and EOR. A: The optimal split was 1, based on k-fold crossvalidation. Patients with a tumor score of 2 were more likely to experience worsened vision postoperatively. B: The optimal split was 3 , based on k-fold cross-validation. The split order was canal score, followed by approach, followed by artery score. The highest rate of GTR was for patients with canal score 0 and artery score 0 . The frequency of GTR declined if there was a higher artery score and a higher canal score and if a TS approach was used.

score $(\mathrm{p}=0.4356)$, artery score $(\mathrm{p}=0.6497)$, total score $(\mathrm{p}=0.4671)$, TC or TS approach $(\mathrm{p}=0.7965)$, or EOR ( $\mathrm{p}$ $=0.3157$ ). Similarly, none of the following variables were significant predictors for recurrence on univariate analysis: tumor score $(\mathrm{p}=0.5481)$, canal score $(\mathrm{p}=0.0731)$, artery score $(p=0.4494)$, total score $(p=0.4451)$, TC or TS approach $(\mathrm{p}=0.5481)$, or EOR $(\mathrm{p}=0.0773)$. Although not significant, there were more recurrences $(n=8 / 48,16.7 \%)$ in the NTR or STR group compared to the GTR group (n $=6 / 91,6.6 \%$ ).

Finally, we performed univariate analysis to compare visual outcomes and EOR between tumors that were stratified by matched grading scale scores and split by TC or TS approach. There were no significant differences in visual outcome between transcranially and transsphenoidally resected tumors when stratified by grading scale score. The frequency of visual outcomes by score is shown in Fig. $5 \mathrm{~A}$. When we performed univariate analysis of EOR by approach and individual tumor score, we found no significant difference between approaches. For tumors with a total score of 5 (tumor 2, canal 2, artery 1), there were more GTRs with the TC approach when analyzed with Pearson's chi-square test $(\mathrm{p}=0.035)$, but this was not significant with Fisher's exact test (OR 11.0, 95\% CI 0.92-130.32; p $=0.0578$ ). The frequency of GTR versus NTR or STR by score is shown in Fig. 5B, and it allows one to appreciate how the difficulty of achieving GTR rises as grading scale score increases. 


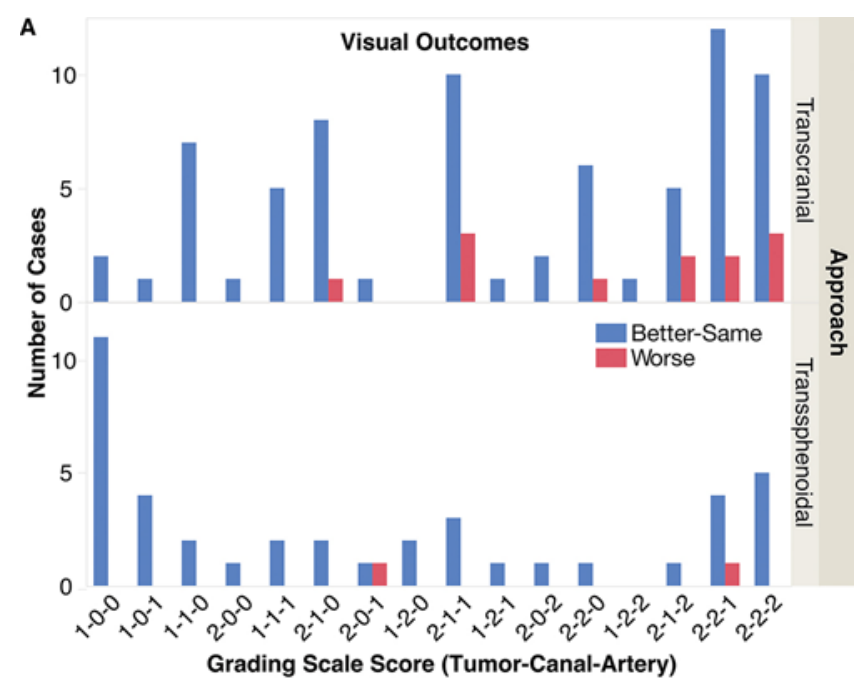

B

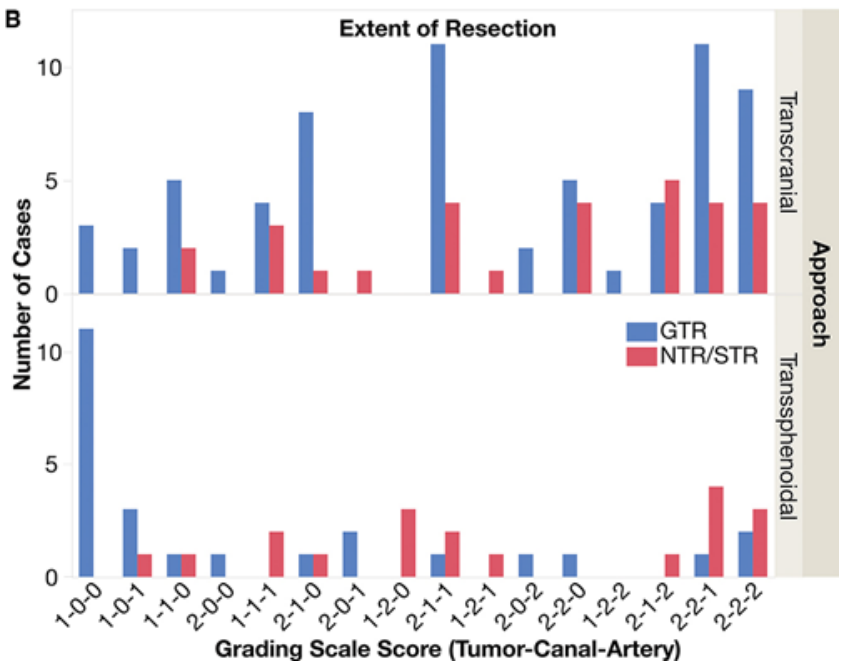

FIG. 5. Visual outcome and EOR frequency by individual tumor score and stratified by TC or TS approach. A: Frequency of better-same or worse visual outcome by approach and by grading scale score. There were no significant differences between visual outcomes by approach when stratified by score. B: Frequency of GTR versus NTR or STR by approach and grading scale score. There were no significant differences by Fisher's exact test.

\section{Discussion}

\section{Key Results}

To our knowledge, this is the largest surgical outcome series of TSMs published to date, and it contains significant numbers of tumors resected with both TC and TS approaches. These tumors can be resected with acceptable morbidity and no mortality, regardless of TC or TS approach. Most patients had stable or improved vision postoperatively and had GTR or NTR. There was no difference in recurrence rates between TC and TS approaches. We present a simple, easy-to-use grading scale for TSMs, which can provide a starting point when evaluating these tumors and selecting the optimal surgical approach for each patient. The tumor component of the scale is significantly associated with postoperative vision outcomes, with higher scores being associated with worse vision outcomes. Similarly, the canal component of the score also is associated with EOR, with higher canal scores being associated with a lower likelihood of achieving GTR.

\section{Interpretation of Results}

This is a notable series for several reasons. First, it is larger than other series ${ }^{1,15,16,20,22,25,30}$ and it is multicenter, including patients from 2 centers that are very experienced in both TC and TS approaches. Second, it combines data from a center that is more biased toward TS approaches (Italy) and one that is historically more biased toward TC approaches (UCSF). Nevertheless, there are still 44 TS cases, which makes this one of the larger TS series of TSM in the literature as well. Within the TC approaches, the majority were extended bifrontal, which reflects the preferred approach of the senior author (M.W.M.). Advantages of the bifrontal approach include the ability to view the whole course and the undersurface of each optic nerve from either the left or the right side. In addition, the bifrontal approach provides bilateral exposure of the roof of the optic canal so that each roof can be removed, which exposes the points of attachment at the junction of the chiasmatic sulcus and optic canal. This allows tumor removal from the medial side of the canal for the first $6-8 \mathrm{~mm}$ of the optic canal. We previously reported the fact that radiographic evidence of retraction injury to the frontal lobes is rare when practitioners use appropriate techniques. ${ }^{3}$ Recently, we started using a tailored bifrontal approach, which allows the orbital bar to be left in place and provides the necessary visibility and working room. ${ }^{26}$ This reduces problems with orbital swelling and ocular motility in the early days postoperatively. For smaller TSMs resected using the TC approach, the orbitozygomatic approach was most commonly used and provides similar advantages to the bifrontal approach, except with less exposure. Others have found similarly good results with the supraorbital subfrontal eyebrow approach, especially when combined with angled endoscopic assistance. ${ }^{30,31}$

Although visual improvement rates have been reported as high as $90 \%-96 \%,,^{20,22}$ improvement is less frequent in large tumors with complex anatomy and long-standing deficits. ${ }^{20}$ Higher tumor score was the only significant variable on univariate analysis to predict visual worsening. There was no difference in visual worsening between TC and TS approaches in this series, which is different from other studies that have shown less visual worsening with the TS approach. Our results suggest that the larger the tumor, the higher the risk for visual worsening, regardless of approach. Another potential cause of postoperative visual worsening is vasospasm of the arteries supplying the optic chiasm, which can be managed by close postoperative monitoring of blood pressure and the use of vasopressors to raise blood pressure in patients who are symptomatic. We titrate the vasopressors according to effect and have used them to reverse postoperative visual loss in several patients. ${ }^{27}$ Thus, we keep all our patients in the ICU for 48 hours postoperatively to monitor vision and raise the blood pressure if they develop deficits.

We used very stringent criteria for GTR, classifying any lesion where the surgeon knowingly left a small bit 
of tumor on the optic nerve or arteries as an NTR, regardless of the radiographic absence of tumor. Our $65 \%$ GTR rate is comparable to the $54 \%$ for complex anatomy tumors and $94 \%$ for simple anatomy tumors seen by Makarenko et al..$^{20}$ Our $10 \%$ recurrence rate is similar to that seen by Bander et al. (12\%) ${ }^{1}$ and Makarenko et al. (13\%). Most patients who presented with recurrence were treated effectively with radiotherapy. Our complication rate was lower than in prior series, $, 11,20,22$ and the $5 \%$ rate of CSF leakage was excellent in comparison. Although the TS approach still had significantly more leaks, the overall rate was quite low, reflecting improvements in closure techniques. ${ }^{18}$

Selecting the best approach for each patient is a nuanced process. It is important to factor in surgeon training and experience and the goals of the operation. The grading scale we proposed is the first one to be proposed that is significantly associated with EOR and visual outcomes. ${ }^{22}$ Whereas some would argue for use of a TS approach whenever possible due to its less invasive nature and early optic nerve decompression, Karsy et al. recently presented findings consistent with this study, showing that excellent results can be achieved with low morbidity by using a TC approach as well. ${ }^{13}$ Patient quality of life is also a very important consideration when selecting a surgical approach. Makarenko et al. showed that patients in whom a complex tumor was approached transcranially had a decline in quality of life, whereas those with simpler anatomy treated via a TS approach had improved quality of life postoperatively. ${ }^{20}$

\section{Limitations of the Study}

This study is limited by its retrospective design. It is also limited by the lack of a standardized visual outcome measure. Ideally, we would have formal visual field testing before and after each case, which is our current practice, but this was not performed during the majority of the cases in this series. Due to lack of information in the electronic medical record, we were not able to obtain clear information on preoperative visual deficits or postoperative visual function for some early patients in the series. These patients were excluded from the visual outcome analysis, but were included in the imaging analysis and EOR evaluation. This study is also limited by selection bias, in that the approach and patient selection reflect the authors' biases. A larger study that includes more centers will be needed to confirm the usefulness of the scale and build on these results. Finally, the numbers in this series were too small to adequately compare outcomes between individual tumor grades, so again a larger study is needed.

\section{Generalizability of Findings}

These results are those of specialized surgeons with a high-volume practice, and thus may not be generalizable to all surgeons or all institutions. Nevertheless, the fact that we included cases from 2 centers in different countries strengthens the generalizability of our findings compared to a single-surgeon series. Other experienced neurosurgeons who are well trained in both open and endoscopic approaches should be able to use the tumor scale and apply our findings to their practice.

\section{Conclusions}

Tuberculum sellae meningiomas are challenging tumors to resect, but can be removed with acceptable morbidity and no, or extremely low, mortality, which represents marked progress from historical series. ${ }^{28}$ The majority of patients will have improvement or stabilization of visual function postoperatively. Whether to use a TC or TS approach is a complex decision based on tumor characteristics, surgeon skill and/or comfort, and patient preference. Despite a lower EOR with the TS approach, there is no difference in recurrence rate, and recurrences or residuals can be safely managed with radiotherapy. Our proposed grading scale can provide a starting point for approach selection and a basis to compare TSMs and outcomes in the future. We are planning a multicenter review of this grading scale to further evaluate its utility.

\section{Acknowledgments}

This work was supported in part by the National Institutes of Health (1F32CA213944-01 to S.T.M.) and by the Linda Wolfe Meningioma Research Endowment. We thank Dr. Charles Wilson, who operated on several of the early patients in this series and was a master technical surgeon. Also we thank Mr. Kenneth X. Probst, for turning our rough sketches into the excellent illustrations in Figs. 1 and 2.

\section{References}

1. Bander ED, Singh H, Ogilvie CB, Cusic RC, Pisapia DJ, Tsiouris AJ, et al: Endoscopic endonasal versus transcranial approach to tuberculum sellae and planum sphenoidale meningiomas in a similar cohort of patients. J Neurosurg 128:40-48, 2018

2. Cappabianca P, Cavallo LM, Esposito F, Solari D: Endoscopic removal of tuberculum sellae meningiomas, in Al-Mefty O (ed): Controversies in Neurosurgery II. New York: Thieme, 2013

3. Chi JH, Parsa AT, Berger MS, Kunwar S, McDermott MW: Extended bifrontal craniotomy for midline anterior fossa meningiomas: minimization of retraction-related edema and surgical outcomes. Neurosurgery 59 (4 Suppl 2): ONS426ONS434, 2006

4. Clark AJ, Jahangiri A, Garcia RM, George JR, Sughrue ME, McDermott MW, et al: Endoscopic surgery for tuberculum sellae meningiomas: a systematic review and meta-analysis. Neurosurg Rev 36:349-359, 2013

5. de Divitiis E, Esposito F, Cappabianca P, Cavallo LM, de Divitiis O: Tuberculum sellae meningiomas: high route or low route? A series of 51 consecutive cases. Neurosurgery 62:556-563, 2008

6. de Notaris M, Solari D, Cavallo LM, D’Enza AI, Enseñat J, Berenguer J, et al: The "suprasellar notch," or the tuberculum sellae as seen from below: definition, features, and clinical implications from an endoscopic endonasal perspective. J Neurosurg 116:622-629, 2012

7. Doglietto F, Prevedello DM, Jane JA Jr, Han J, Laws ER Jr: Brief history of endoscopic transsphenoidal surgery-from Philipp Bozzini to the First World Congress of Endoscopic Skull Base Surgery. Neurosurg Focus 19(6):E3, 2005

8. Ganna A, Dehdashti AR, Karabatsou K, Gentili F: Frontobasal interhemispheric approach for tuberculum sellae meningiomas; long-term visual outcome. Br J Neurosurg 23:422-430, 2009

9. Goel A, Muzumdar D, Desai KI: Tuberculum sellae meningioma: a report on management on the basis of a surgical experience with 70 patients. Neurosurgery 51:1358-1364, 2002 
10. Guthikonda B, Tobler WD Jr, Froelich SC, Leach JL, Zimmer LA, Theodosopoulos PV, et al: Anatomic study of the prechiasmatic sulcus and its surgical implications. Clin Anat 23:622-628, 2010

11. Hadad G, Bassagasteguy L, Carrau RL, Mataza JC, Kassam A, Snyderman $\mathrm{CH}$, et al: A novel reconstructive technique after endoscopic expanded endonasal approaches: vascular pedicle nasoseptal flap. Laryngoscope 116:1882-1886, 2006

12. Hayhurst C, Sughrue ME, Gore PA, Bonney PA, Burks JD, Teo C: Results with expanded endonasal resection of skull base meningiomas technical nuances and approach selection based on an early experience. Turk Neurosurg 26:662-670, 2016

13. Karsy M, Raheja A, Eli I, Guan J, Couldwell WT: Clinical outcomes with transcranial resection of the tuberculum sellae meningioma. World Neurosurg 108:748-755, 2017

14. Kassam A, Snyderman CH, Mintz A, Gardner P, Carrau RL: Expanded endonasal approach: the rostrocaudal axis. Part I. Crista galli to the sella turcica. Neurosurg Focus 19(1):E3, 2005

15. Khan OH, Anand VK, Schwartz TH: Endoscopic endonasal resection of skull base meningiomas: the significance of a "cortical cuff" and brain edema compared with careful case selection and surgical experience in predicting morbidity and extent of resection. Neurosurg Focus 37(4):E7, 2014

16. Khan OH, Krischek B, Holliman D, Klironomos G, Kucharczyk W, Vescan A, et al: Pure endoscopic expanded endonasal approach for olfactory groove and tuberculum sellae meningiomas. J Clin Neurosci 21:927-933, 2014

17. Kshettry VR, Elshazly K, Evans JJ: Endoscopic transnasal surgery for planum and tuberculum sella meningiomas: decision-making, technique and outcomes. CNS Oncol 5:211-222, 2016

18. Kulwin C, Schwartz TH, Cohen-Gadol AA: Endoscopic extended transsphenoidal resection of tuberculum sellae meningiomas: nuances of neurosurgical technique. Neurosurg Focus 35(6):E6, 2013

19. Mahmoud M, Nader R, Al-Mefty O: Optic canal involvement in tuberculum sellae meningiomas: influence on approach, recurrence, and visual recovery. Neurosurgery 67 (3 Suppl Operative):ons108-ons119, 2010

20. Makarenko S, Carreras EM, Akagami R: Craniotomy for perisellar meningiomas: comparison of simple (appropriate for endoscopic approach) versus complex anatomy and surgical outcomes. J Neurosurg 126:1191-1200, 2017

21. Mathiesen T, Kihlström L: Visual outcome of tuberculum sellae meningiomas after extradural optic nerve decompression. Neurosurgery 59:570-576, 2006

22. Mortazavi MM, Brito da Silva H, Ferreira M Jr, Barber JK, Pridgeon JS, Sekhar LN: Planum sphenoidale and tuberculum sellae meningiomas: operative nuances of a modern surgical technique with outcome and proposal of a new classification system. World Neurosurg 86:270-286, 2016

23. Nakamura M, Roser F, Struck M, Vorkapic P, Samii M: Tuberculum sellae meningiomas: clinical outcome considering different surgical approaches. Neurosurgery 59:1019-1029, 2006

24. Nanda A, Ambekar S, Javalkar V, Sharma M: Technical nuances in the management of tuberculum sellae and diaphragma sellae meningiomas. Neurosurg Focus 35(6):E7, 2013

25. Nimmannitya P, Goto T, Terakawa Y, Sato H, Kawashima T, Morisako H, et al: Characteristic of optic canal invasion in 31 consecutive cases with tuberculum sellae meningioma. Neurosurg Rev 39:691-697, 2016

26. Safaee MM, McDermott MW, Benet A, Theodosopoulos PV: Tailored extended bifrontal craniotomy for anterior skull base tumors: anatomic description of a modified surgical technique and case series. Oper Neurosurg (Hagerstown) [epub ahead of print], 2017

27. Santarius T, Jian BJ, Englot D, McDermott MW: Delayed neurological deficit following resection of tuberculum sellae meningioma: report of two cases, one with permanent and one with reversible visual impairment. Acta Neurochir (Wien) 156:1099-1102, 2014

28. Symon L, Rosenstein J: Surgical management of suprasellar meningioma. Part 1: The influence of tumor size, duration of symptoms, and microsurgery on surgical outcome in 101 consecutive cases. J Neurosurg 61:633-641, 1984

29. von Elm E, Altman DG, Egger M, Pocock SJ, Gøtzsche PC, Vandenbroucke JP: The Strengthening the Reporting of Observational Studies in Epidemiology (STROBE) statement: guidelines for reporting observational studies. PLoS Med 4:e296, 2007

30. Wilk A, Zieliński G, Witek P, Koziarski A: Outcome assessment after surgical treatment of tuberculum sellae meningiomas-a preliminary report. Turk Neurosurg 26:824-832, 2016

31. Wilson DA, Duong H, Teo C, Kelly DF: The supraorbital endoscopic approach for tumors. World Neurosurg 82 (6 Suppl):S72-S80, 2014

\section{Disclosures}

The authors report no conflict of interest concerning the materials or methods used in this study or the findings specified in this paper.

\section{Author Contributions}

Conception and design: McDermott, Aghi, Theodosopoulos, Berger, de Divitiis, Solari, Cappabianca, Cavallo. Acquisition of data: McDermott, Magill, Morshed, Lucas, Berger, de Divitiis, Solari, Cappabianca, Cavallo. Analysis and interpretation of data: McDermott, Magill, Morshed, Aghi, de Divitiis, Solari, Cappabianca, Cavallo. Drafting the article: McDermott, Magill, Morshed. Critically revising the article: McDermott, Magill, Morshed, Aghi, Theodosopoulos, de Divitiis, Solari, Cappabianca, Cavallo. Reviewed submitted version of manuscript: McDermott, Magill, Morshed, Aghi, Theodosopoulos, Cappabianca, Cavallo. Approved the final version of the manuscript on behalf of all authors: Magill. Statistical analysis: McDermott, Magill. Study supervision: McDermott, Magill, Cappabianca, Cavallo.

\section{Supplemental Information}

\section{Previous Presentations}

Preliminary results were given in an oral presentation at the 2017 North American Skull Base Society Annual Meeting (New Orleans, LA).

\section{Correspondence}

Michael W. McDermott: University of California, San Francisco, CA.mike.mcdermott@ucsf.edu. 